\title{
Reconsidering overlap in global food security governance
}

\author{
Angela Heucher ${ }^{1}$
}

Received: 26 April 2018 / Accepted: 28 March 2019 /Published online: 16 May 2019

(C) International Society for Plant Pathology and Springer Nature B.V. 2019

Overlap among international organizations (IOs) ${ }^{1}$ is one of the numerous challenges facing global food security governance today. The phenomenon of overlap has received attention in academic debates on food security, as Candel (2014) shows in his comprehensive literature review. My objective in this opinion piece is to reflect on three widespread, common assumptions depicting overlap as a phenomenon that is a) recent, b) undesirable, and c) manageable and solvable. Before elaborating on these assumptions in turn, I first conceptualize overlap by referring to relevant literature and then briefly introduce the empirical research on which the opinion piece builds.

Despite its widespread usage, the term overlap remains somewhat vague. According to Gehring and Faude (2014, p. 474), overlap entails "that the memberships, as well as the regulatory scopes, of two or more separately established international institutions overlap". This can be detrimental if rules between institutions conflict and states have the opportunity to engage in forum shopping, which can undermine the institutionalist logic of cooperation (Drezner 2009). Drawing on the regime complex concept, Margulis (2013) argues that conflicts can emerge between actors in food security governance even though there are no overlapping formal rules. As an example, Margulis points to the conflict between the World Trade Organization (WTO) and the World Food Programme (WFP) on food aid rules. In a similar vein, international law literature has discussed questions of fragmentation and linkages among different regimes, in particular between trade and human rights regimes (Gonzalez-Pelaez 2005; Joseph 2013).

\footnotetext{
${ }^{1}$ While food security governance is shaped through the activities of very different types of actors, such as IOs, non-governmental organizations (NGOs) and the private sector, the emphasis of this piece is on overlap among IOs, rather than between different types of actors. Of course, this is not to say that overlap doesn't occur among different types of actors or that such overlap isn't relevant - it merely constitutes a choice of emphasis.
}

\section{Angela Heucher}

angela.heucher@uni-potsdam.de

1 University of Potsdam, Potsdam, Germany
In her analysis of the compatibility between the WTO's agricultural trade rules and the human right to food, Ferguson (2018) argues that no technical conflict between the two regimes exists. Nonetheless, she posits that they can affect each other, underlining that a lack of technical conflict "does not mean that the rules in question are harmonious, or that international trade law is supportive of the key elements of the right to food" $(2018$, p. 269). In light of this, what I find interesting in relation to overlap are the manifold linkages and effects which emerge when two or more IOs are active in the same field and co-govern an issue area, and when the work of one actor intersects with the work of another.

Empirically, this piece is informed by my own research on the United Nations Food and Agriculture Organization (FAO) and the United Nations Industrial Development Organization (UNIDO). ${ }^{2}$ I conducted a computer-assisted qualitative content analysis of organizational documents, e.g. IO governing bodies' reports and strategic plans, covering time frames from 1945 to 2017 (FAO) and from 1986 to 2017 (UNIDO). I also include observations from an empirical analysis of the field of food security governance in Côte d'Ivoire, where I interviewed IO staff in February-March 2016. Finally, I incorporate secondary literature on the state of governance of global food security (e.g., Clapp 2014; Margulis 2017; McKeon 2015; Shaw 2007).

Turning to the common assumptions about overlap, a first and at times implicit one is that overlap is a recent phenomenon. In the literature on food security governance, proliferation, overlap and fragmentation are often discussed in the context of the food price and hunger crises of the 1970s and of 2007/08 (Clapp 2014; McKeon 2015; Shaw 2007). These were decisive events with far-reaching effects on the architecture of the governance of food security, which constantly changes for a variety of reasons, be they political, economic or social (see Shaw 2007 for a history of food security since 1945). At the same time, overlap has historical

\footnotetext{
${ }^{2}$ In essence, these are the two cases I focused on in my dissertation, where I analysed how the position of an IO within the organizational field of food security governance, be it at the core (FAO) or at the periphery (UNIDO), matters for IO perceptions of and responses to field developments, e.g., overlap.
} 
roots which go further back and may even qualify as a foundational element of the UN system. ${ }^{3}$ FAO, as the first IO to be given a global mandate to work on issues of food insecurity and hunger, ${ }^{4}$ was concerned about overlap from the beginning: at its first session, the FAO Conference recommended to its members that predecessor organizations - the International Institute of Agriculture (IIA) and the Comité International du Bois - should be dismantled as the Conference was "desirous of avoiding overlapping and duplication of effort among international organizations" (FAO 1945). Even though these two specific organizations were dismantled, the concern with overlap nonetheless remained. It was then directed at other IOs, such as the WFP, which FAO saw as an IO whose activities had progressively overlapped with its own work (FAO 2013).

The second common assumption centers on the undesirability of overlap. This assumption is held both by scholars and by IOs themselves and becomes apparent in the language used to depict overlap. As Candel (2014) emphasizes in his review, overlap is identified in the literature as a "problem" of food security governance, next to fragmentation, conflict and ineffectiveness. For instance, overlap can pose a problem for member countries if two IOs offer conflicting policy advice on the same issue, which creates uncertainty. FAO governing bodies voiced fears early on regarding overlap and duplication of work, and understood it to be a development which should be avoided. For instance, the FAO Council, in referring to publications on food and population planned by the United Nations Educational, Scientific and Cultural Organization (UNESCO), called on FAO and UNESCO to take steps to "to safeguard against duplication of effort" (FAO 1948, p. 1, own emphasis). In a similar vein, UNIDO depicted overlap as undesirable when acknowledging that "UNIDO programmes in the past were overlapping with those of other actors which has, at times, given rise to justified criticism" (UNIDO 1998, p. 8, own emphasis).

To be clear, I do not claim that overlap may not lead to detrimental outcomes. I do contend, however, that this is an empirical question and that there may be another side to overlap. For instance, literature on the governance of food security as a "wicked problem" (Candel et al. 2015; Termeer et al. 2015) points out that a certain degree of redundancy in a system may actually help actors such as the European Commission when dealing with complicated food security

\footnotetext{
3 The UN General Assembly (1949) passed a resolution as early as 1949 on the "problem of the proliferation and overlapping of the programmes of the United Nations and of the specialized agencies".

${ }^{4}$ Although explicit references to the objective of eliminating world hunger were only added to the preamble of the FAO Constitution in 1965 (Marchisio and Di Blase 1991, p. 12).
}

issues. Moreover, when conducting interviews with IO-staff on food security governance in Côte d'Ivoire, one interview partner argued that overlap existed, but was not too problematic given the serious needs of the population. Overlap was thus acceptable for the time being. Furthermore, in debates on overlap at the FAO Conference in 1989, some countries did posit that other IOs overlapping with FAO was "harming the lead role of FAO" (FAO 1989, para. 220), as other IOs were receiving funding to work on issues within FAO's mandate. Other countries, however, did not share the judgment that overlap was a problem. Rather, they suggested that the quality of work was decisive and that a certain degree of competitiveness was nothing to worry about. These observations imply that more clarity is needed: What do we mean exactly when we talk about overlap? Is some overlap acceptable (for a limited time period)? How do we assess whether and under what conditions overlap has positive or detrimental effects, and for what and whom?

A third common assumption is that overlap is manageable and solvable. This assumption can be found in many IO documents. For instance, when noting overlap with Regional Economic Commissions (RECs) as early as 1951, FAO posited that "coordinated action in fields of mutual interest can be brought about through cooperative planning" (FAO 1951, p. 2). However, debates on overlap are a recurring theme in FAO documents from 1945 to 2017 and the issue even appears to worsen over time: while the discourse in the early years revolved around the need to avoid or prevent overlap, it later on shifted to the necessity of reducing overlap. Besides using coordinated action to manage overlap (see also UNIDO 2008 on "inter-agency coordination across the system" as a means to address overlap and duplication), one interview partner reasoned that overlap would not be an issue if each organization would "go back" to its mandate. This assumption, however, is not fully convincing. Organizational mandates reflect members' (conflicting) expectations towards IOs at specific moments in time. With regard to FAO, members envisioned two different roles for the organization: a data collecting discussion forum and an activist organization (Staples 2006). Mandates and accordingly roles may thus be ambiguous in themselves and be the subject of constant reinterpretation and renegotiation. They do not necessarily offer clear-cut guidance.

Also, while different institutions exist today which shape the governance of food security and aim at coordination and coherence, such as the global food security cluster in humanitarian emergencies (Maxwell and Parker 2012), the Committee on World Food Security (CFS), the High Level Task Force's Comprehensive Framework for Action (CFA), or the G8/G20 (Margulis 2012), coordination is not 
always easy. The body once explicitly established with the purpose of ensuring coordination in the field of food security governance in the 1970s, the World Food Council (WFC), was disbanded in the 1990s for a range of different reasons, among them a lack of authority and resources, and some UN agencies resenting the WFC and seeing its establishment as "unnecessary" (Shaw 2007, p. 219). These observations somewhat question the idea that outcomes will emerge if IOs have the intention of achieving a certain goal, e.g. improved coordination, or that what happens in global food security governance necessarily reflects "rational" behavior. The field of global food security governance has experienced transformations over time (Shaw 2007). Importantly, there are diverse drivers for organizational behavior and outcomes at the aggregate level, such as overlap, and these may be beyond the control of an individual IO or specifically tasked coordination bodies.

If overlap is both a fairly enduring feature of food security governance and difficult to solve, IOs may need to adapt accordingly. While this piece took FAO as a primary example, this also holds for other IOs active in food security governance, such as WFP. To begin with, this would entail recognizing the longer history of overlap (and the many attempts to manage or solve it) and questioning one's own assumptions on overlap. Such an awareness would be important to be able to decide when overlap requires a response (by whom and for what), and when it may be acceptable. Finally, while overlap is often depicted as undesirable - and while this may be the case - there are some theoretical arguments and observations which point to another side of the story. At the very least, further empirical investigation is necessary to arrive at a more nuanced understanding of overlap.

Acknowledgements Research informing this opinion piece was conducted when the author worked as a researcher at the Collaborative Research Center (SFB) 700 "Governance in Areas of Limited Statehood" in the research project 'Talk and Action'. How International Organizations Respond to Areas of Limited Statehood". Funding by the German Research Foundation (DFG) under grant SFB 700/3, D08 is gratefully acknowledged. Furthermore, I thank Jennifer Clapp, the two anonymous reviewers and the editor for valuable and constructive comments.

\section{Compliance with ethical standards}

Conflict of interest The author declared to have no conflict of interest.

\section{References}

Candel, J. J. L. (2014). Food security governance: A systematic literature review. Food Security, 6(4), 585-601.
Candel, J. J. L., Breeman, G. E., \& Termeer, C. J. A. M. (2015). The European Commission's ability to deal with wicked problems: An in-depth case study of the governance of food security. Journal of European Public Policy, 23, 1-25. https://doi.org/10.1080/ 13501763.2015.1068836.

Clapp, J. (2014). Food and hunger. In T. G. Weiss (Ed.), International organization and global governance (pp. 644-655). London: Routledge.

Drezner, D. D. (2009). The power and peril of international regime complexity. Perspectives on Politics, 7(1), 65-70.

FAO. (1945). Report of the conference of FAO - First session: Appendix I. City of Quebec, Canada, 16 October - 1 November 1945. http:// www.fao.org/docrep/x5584E/x5584e0d.htm\#relations. Accessed 14 February 2018.

FAO. (1948). FAO Council: Fourth session: Report of the committee on relations with international organizations (CL4/11). Washington, D.C., 8 November 1948.

FAO. (1951). FAO Council: Twelfth session: Report of the DirectorGeneral on relations with other international organizations, Rome, 11-25 June 1951. CL12/22. Rome.

FAO. (1989). Report of the conference of FAO: Twenty-fifth session: D. Conclusions of the review of certain aspects of FAO's goals and operations. 11-29 November 1989, Rome. Accessed 21 March 2018.

FAO. (2013). FAO's attributes, core functions and comparative advantages. CL 144/14 Web Annex. Rome.

Ferguson, R. (2018). The right to food and the World Trade Organization's rules on agriculture: Conflicting, compatible, or complementary? Boston: BRILL.

Gehring, T., \& Faude, B. (2014). A theory of emerging order within institutional complexes: How competition among regulatory international institutions leads to institutional adaptation and division of labor. The Review of International Organizations, 9(4), 471-498.

Gonzalez-Pelaez, A. (2005). Human rights and world trade: Hunger in international society. London: Routledge.

Joseph, S. (2013). Blame it on the WTO: A human rights critique. Oxford: Oxford University Press.

Marchisio, S., \& Di Blase, A. (1991). The Food and Agriculture Organization (FAO). Dordrecht: Martinus Nijhoff Publishers.

Margulis, M. (2012). Global food security governance: The Committee on World Food Security, comprehensive framework for action and the G8/G20. In R. G. Rayfuse \& N. Weisfelt (Eds.), The challenge of food security: International policy and regulatory frameworks (pp. 231-254). Cheltenham, Northampton: Edward Elgar.

Margulis, M. (2013). The regime complex for food security: Implications for the global hunger challenge. Global Governance, 19(1), 53-67.

Margulis, M. (2017). The global governance of food security. In J. A. Koops \& R. Biermann (Eds.), Palgrave handbook of interorganizational relations in world politics (pp. 503-525). Basingstoke: Palgrave Macmillan.

Maxwell, D., \& Parker, J. (2012). Coordination in food security crises: A stakeholder analysis of the challenges facing the global food security cluster. Food Security, 4(1), 25-40.

McKeon, N. (2015). Food security governance: Empowering communities, regulating corporations. Abingdon: Routledge.

Shaw, D. J. (2007). World food security: A history since 1945. Basingstoke: Palgrave Macmillan.

Staples, A. L. S. (2006). The birth of development: How the World Bank, Food and Agriculture Organization, and World Health Organization have changed the world, 1945-1965. Kent: Kent State University Press. 
Termeer, C. J. A. M., Dewulf, A., Breeman, G., \& Stiller, S. J. (2015). Governance capabilities for dealing wisely with wicked problems. Administration \& Society, 47, 680-710. https://doi.org/10.1177/ 0095399712469195 .

UN General Assembly. (1949). Problem of the proliferation and overlapping of the programmes of the United Nations and of the specialized agencies: Resolution 310 (IV). https://documents-dds-ny.un.org/ doc/RESOLUTION/GEN/NR0/051/29/IMG/NR005129.pdf? OpenElement. Accessed 30 March 2018.

UNIDO. (1998). Opening statement of the Director-General: 19th Session of the Industrial Development Board, 18 may 1998, Vienna, Austria. Vienna. https://www.unido.org/resources/ policymaking-organs/industrial-development-board/sessions/ 19th-session/opening-statement-director-general. Accessed 18 April 2018.

UNIDO. (2008). Report of the industrial development board on the work of its thirty-fourth session, 14-16 May 2008, Vienna, Austria: General conference, thirteenth session, 7-11 December 2009, Vienna, Austria. GC.13/2. Vienna. https:// www.unido.org/sites/default/files/2009-10/GC.13_2e_0.pdf. Accessed 19 April 2018.

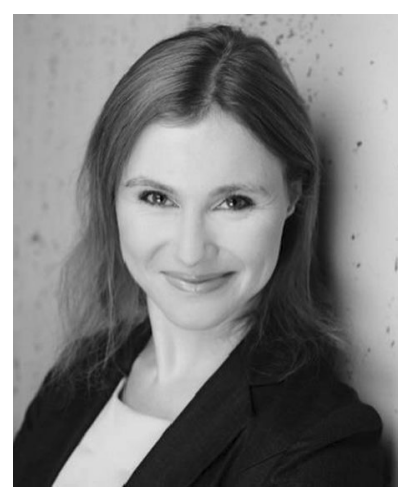

Angela Heucher recently received her doctorate degree in political science from University of Potsdam. From 2014 to mid2018, she worked as a research associate at the University of Potsdam and Freie Universität Berlin and was a research affiliate at the Berlin Graduate School for Transnational Studies. Situated at the Collaborative Research Center (SFB) 700 "Governance in Areas of Limited Statehood", she was part of a research team examining the role of international organizations as external governance actors ("“Talk and Action': How International Organizations Respond to Areas of Limited Statehood"). The project analyzed how international organizations see their own role as well as opportunities and challenges regarding their operations in the contexts of different countries. Her research interests include international organizations, inter-organizational relations, food security, as well as organizational perceptions of and responses to overlap in global food security governance. 